\title{
A New HPLC Validated Method for Therapeutic Monitoring Of Triazoles in Human Plasma: First Results in Leukaemic Patients
}

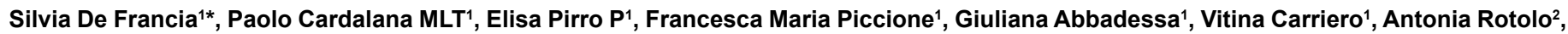
Marco De Gobbi ${ }^{2}$, Angelo Guerrasio ${ }^{2}$, Silvia Racca ${ }^{1}$ and Giuseppe Reimondo ${ }^{3}$

${ }^{1}$ Clinical Pharmacology, Department of Clinical and Biological Sciences, University of Turin, S. Luigi Gonzaga Hospital, Regione Gonzole 10, 10043 Orbassano (TO), Italy ${ }^{2}$ Haematology, Department of Clinical and Biological Sciences, University of Turin, S. Luigi Gonzaga Hospital, Regione Gonzole 10, 10043 Orbassano (TO), Italy IInternal Medicine, Department of Clinical and Biological Sciences, University of Turin, S. Luigi Gonzaga Hospital, Regione Gonzole 10, 10043 Orbassano (TO), Italy

\section{Abstract}

Therapeutic drug monitoring of triazoles is widely used in clinical practice to optimize therapy, especially in those patients who need antifungal treatment as co-medications. Here it is described development and validation of a new chromatographic method in order to quantify voriconazole and posaconazole in human plasma by ultraviolet detection.

After liquid extraction of analytes from plasma using acetonitrile, samples are evaporated to dryness and then reconstituted in mobile phase for chromatographic separation. Analysis is achieved on $\mathrm{C} 18$ reverse phase column and eluate is monitored at $250 \mathrm{~nm}$. Mobile phase consisted of $35 \%$ water, $15 \%$ methanol, $50 \%$ acetonitrile. Flavone was used as internal standard; retention times (minutes) were, respectively, for voriconazole 3.9, posaconazole 7.9, flavone 7.1 .

Accuracy and variability were assayed by inter- and intra-day validation, conducted on three separate days. Methodology was used for the analysis of plasma samples of acute myeloid leukaemia patients in therapy with voriconazole or posaconazole for treatment of fungal infections, in order to perform therapeutic monitoring of antifungal drugs levels.

Mean inter- and intra-day accuracy and variability were acceptable for both compounds; thus, method developed resulted linear in the range $0.125-8 \mu \mathrm{g} / \mathrm{mL}$. Limits of quantification and limits of detection for voriconazole and posaconazole are, respectively, 0.100 and $0.050 \mu \mathrm{g} / \mathrm{mL}$, and 0.030 and $0.020 \mu \mathrm{g} / \mathrm{mL}$.

It has been observed that voriconazole and posaconazole circulating levels achieved in patients are on average below the therapeutic range defined in literature.

In conclusion, method developed and validated in order to quantify voriconazole and posaconazole in human plasma is accurate and precise; it is easily applicable and reproducible, and, therefore, it could be an useful tool in clinical routine to better manage patients in case of multi-therapy approach.

Keywords: HPLC; Voriconazole; Posaconazole; Quantification; Leukemia

\section{Introduction}

Due to polypharmacy and complexity of comorbidities in haematology patient population, antifungal therapy may be often associated with significant toxicity or drug interactions, leading to sub-therapeutic antifungal drug concentrations and poorer clinical outcomes [1]. Antifungal agents of the azole class are metabolized by the cytochrome P450 (CYP450) system, such as voriconazole (VRC, Figure 1), a widely used broad-spectrum triazole substrate of

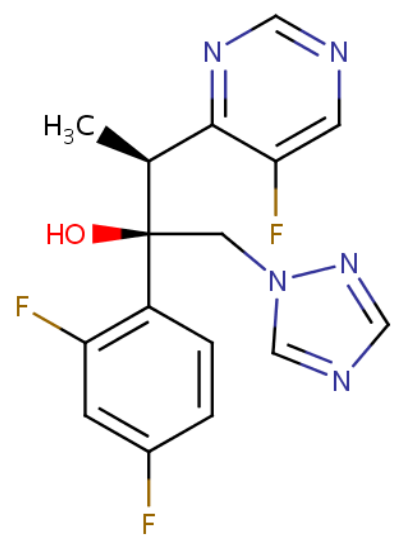

Figure 1: Structure of Voriconazole
CYP2C19, CYP3A4 and CYP2C9 isoforms [2]. Posaconazole (PSC, Figure 2), instead, likewise broad-spectrum triazole, is also substrate of CYP3A4 but primarly undergoes glucuronidation [3,4], leading to a potential for drug-drug interactions minor than that for VRC [1]. Then, co-administration of drugs that induce CYP450 metabolism can result in undetectable circulating levels of VRC and PSC, while coadministration of CYP450 inhibitors may cause an increase of these levels. On the other hand VRC inhibits CYP3A4 isoform, and even more stronger inhibitor is PSC, leading to an increase of circulating levels of drugs metabolized by CYP3A4. Although antifungal therapy does not typically fulfill all criteria needed for Therapeutic Drug Monitoring (TDM) indication [5], assessment of circulating levels achieved in patients may be helpful for antifungal agents where non-compliance,

*Corresponding author: Silvia De Francia, Clinical Pharmacology, Department of Clinical and Biological Sciences, University of Turin, S. Luigi Gonzaga Hospital, Regione Gonzole 10, 10043 Orbassano (TO), Italy,Tel: + 39011 6705442; Fax: + 39 011 9038639;E-mail: silvia.defrancia@unito.it

Received: August 28, 2015; Accepted: September 18, 2015; Published: September 23, 2015

Citation: Francia SD, Cardalana MLT, Pirro EP, Piccione FM, Abbadessa G, et al (2015) A New HPLC Validated Method for Therapeutic Monitoring Of Triazoles in Human Plasma: First Results in Leukaemic Patients Clin Exp Pharmacol 5: 189. doi:10.4172/2161-1459.1000189

Copyright: (c) 2015 Dakheel SD, et al. This is an open-access article distributed under the terms of the Creative Commons Attribution License, which permits unrestricted use, distribution, and reproduction in any medium, provided the original author and source are credited. 


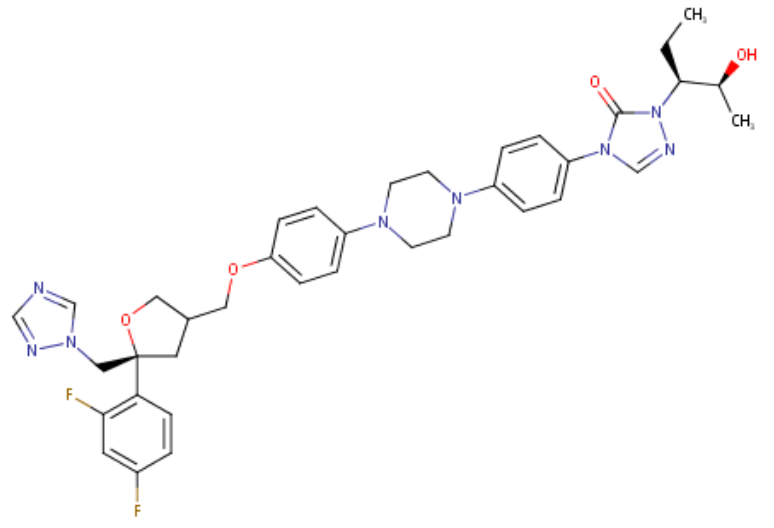

Figure 2: Structure of Posaconazole

non-linear pharmacokinetics, a narrow therapeutic window, drugs interactions or unexpected toxicity are encountered, all factors that may even worsen for haematology population.

VRC exhibits ca.100-fold variability in drug levels in individuals receiving the same dose [6], showing non-linear saturable pharmacokinetics [7]. To our knowledge available recommendations suggest that VRC levels should be maintained $>1 \mathrm{~g} / \mathrm{mL}$ and that levels $>5.5 \mathrm{~g} / \mathrm{mL}$ have been reported to be possibly associated with toxicity [8]. Furthermore, polymorphisms in the CYP2C19 isoform are associated with slow VRC metabolism and may lead to two- to four folds higher VRC exposure [9]. Corroborating the potential of drug-drug interactions, it's known that in patients with haematologic malignancy, the correlation between VRC concentration and daily dose is poor [10].

Less data are available in literature for PSC. It is known that PSC shows high inter-patient variability [11]. Furthermore, exposureresponse analyses revealed a clear relationship between an higher incidence of clinical failure and lower PSC circulating concentrations, suggesting that it is necessary to ensure adequately high plasma exposure to PSC, in terms of prophylaxis and treatment of fungal infections both $[7,11,12]$.

TDM has become recently an essential tool for the management of patients with different pathologies and may be useful, then, also for haematologic patients treated with azoles for fungal infections, especially if drugs administered for haematologic disorder may tamper with antifungal agents.

Daunorubicin and cytarabine are current therapy for acute myeloid leukaemia (AML) treatment. These drugs are all metabolized by CYP3A4; furthermore, daunorubicin, inhibits CYP450 isoforms, especially CYP3A4. Then, drug interactions involving CYP450 in AML patients treated with azoles for fungal infections may play a central role.

Therefore, quantification of circulating azoles levels is an important issue in clinical practice to improve efficacy, minimizing toxicity, especially in selected populations, such as AML patients.

In recent years, many methods to quantify azoles in human plasma individually and simultaneously have been published. Several reported the use of high performance liquid chromatography coupled with ultraviolet determination (HPLC-UV)[4,13-24]. More recently, liquid chromatographic methods based on mass spectrometry (LC-MS/MS) detection have been developed to this purpose [25-32], although MS facilities are not always available in standard hospital laboratories, because they are expensive compared with a simple HPLC system.
The aim of the current work was to develop and validate a reliable HPLC-UV method for the simultaneous determination of VRC and PSC in human plasma, easily suitable in routine TDM for selected population such as AML patients.

\section{Materials and Methods}

\section{Chemicals and reagents}

VRC was kindly provided by Pfizer (Sandwich, United Kingdom) and PSC was kindly provided by MSD/Schering-Plough (Wicklow, Ireland); flavone, used as internal standard (IS), because structurally analogue of voriconazole and PSC, was purchased from Sigma-Aldrich (Milan, Italy). Acetonitrile and methanol HPLC grade were purchased from VWR International (Milan, Italy); HPLC grade water was produced with Milli DI system coupled with a Synergy 185 system by Millipore (Milan, Italy). Blank plasma from healthy donors was kindly supplied by the Blood Bank of San Luigi Hospital (Orbassano, Italy).

\section{Stock solutions, calibration standards and quality controls}

Stock solutions of VRC, PSC and flavone were prepared by dissolving an accurately weighed amount of drug in methanol to obtain a final concentration of $1 \mathrm{mg} / \mathrm{mL}$, then stored at $-20^{\circ} \mathrm{C}$ for no longer than 3 months, based on stability data shown in previously published works $[33,34]$. A working solution of IS was prepared daily at a concentration of $25 \mu \mathrm{g} / \mathrm{mL}$ in methanol. Stock solutions of VRC and PSC were used to prepare plasma calibration standards samples (STDs) and quality controls (QCs). The highest calibration standard (STD7: 8 $\mu \mathrm{g} / \mathrm{mL})$ and 4 QCs, QC high $(5 \mu \mathrm{g} / \mathrm{mL})$, QC medium $(1 \mu \mathrm{g} / \mathrm{mL})$, QC low $(0.25 \mu \mathrm{g} / \mathrm{mL}$ for VRC and $0.2 \mu \mathrm{g} / \mathrm{mL}$ for PSC) and QC as lower limit of quantification (LLOQ; $0.1 \mu \mathrm{g} / \mathrm{mL}$ for VRC and $0.03 \mu \mathrm{g} / \mathrm{mL}$ for PSC), were prepared adding a determined volume of stock solution to blank plasma. Others STDs were prepared daily by serial dilution from STD7 to the lowest calibration standard (STD1: $0.125 \mu \mathrm{g} / \mathrm{mL}$ ) with blank plasma, to obtain 7 different spiked concentrations. A blank sample plus IS (STD0) was also included. Calibration range, from STD7 to STD1, and QCs concentrations are listed in table 1. STDs and QCs were stored at $-20^{\circ} \mathrm{C}$ for no longer than 3 months, based on stability data shown in previously published works $[33,34]$.

\section{Patients}

Plasma samples were obtained in TDM routine activity from AML patients admitted to the Haematology ward of San Luigi Gonzaga Hospital (Orbassano, Italy) undergoing treatment with VRC $(\mathrm{n}=23$ : 13 males, 10 females; $200 \mathrm{mg}$ twice daily) or PSC ( $\mathrm{n}=14 ; 11$ males, 3 females; $200 \mathrm{mg}$ three times daily) for prophylaxis or therapy purposes. All patients were treated for at least 7 days before blood sampling, so that collection was done at steady state. Blood samples were collected in lithium heparin tube at the $\mathrm{C}$ trough $(12 \pm 3$ hours after last drug intake). Plasma samples were obtained by centrifugation at $700 \mathrm{~g}$ for $10 \mathrm{~min}$ at $4^{\circ} \mathrm{C}$, then frozen at $-20^{\circ} \mathrm{C}$ till analysis. Blood samples were taken immediately before drug intake. Written informed consensus was

\section{VORICONAZOLE}

\begin{tabular}{l|l|l|l|l|l|l|l|l|l|l|l|l} 
STD $_{1}$ & $\mathbf{S T D}_{2}$ & $\mathbf{S T D}_{3}$ & $\mathbf{S T D}_{4}$ & $\mathbf{S T D}_{5}$ & $\mathbf{S T D}_{6}$ & $\mathbf{S T D}_{7}$ & $\mathbf{Q C}_{1}$ & $\mathbf{Q C}_{\mathrm{m}}$ & $\mathbf{Q C}_{\mathrm{h}}$ & LLOQ & LOD
\end{tabular}

$\begin{array}{lllllllllllllll}0.125 & 0.25 & 0.5 & 1 & 2 & 4 & 8 & 0.25 & 1 & 5 & 0.1 & 0.05\end{array}$

POSACONAZOLE

\begin{tabular}{|l|l|l|l|l|l|l|l|l|l|l|l|}
\hline $\mathbf{S T D}_{1}$ & $\mathbf{S T D}_{2}$ & $\mathbf{S T D}_{3}$ & $\mathbf{S T D}_{4}$ & $\mathbf{S T D}_{5}$ & $\mathbf{S T D}_{6}$ & $\mathbf{S T D}_{7}$ & $\mathbf{Q C}$ & $\mathbf{Q C}_{\mathrm{m}}$ & $\mathbf{Q C}_{\mathrm{h}}$ & LLOQ & LOD
\end{tabular}

\begin{tabular}{l|l|l|l|l|l|l|l|l|l|l|l}
0.125 & 0.25 & 0.5 & 1 & 2 & 4 & 8 & 0.2 & 1 & 5 & 0.03 & 0.02
\end{tabular}

Table 1: Calibrations Standards from STD to STD $_{7}$, Quality Controls (low, medium high), Lower Limit of Quantification (LLOQ) and Lower Limit of detection (LOD) concentrations $(\mu \mathrm{g} / \mathrm{mL})$ for voriconazole and posaconazole. 
reached from patients and approval for the research was obtained from local ethics committee.

Developed method was also used to measure the two drugs in plasma samples for the International Interlaboratory Quality Control Program for Therapeutic Drug Monitoring of Antifungal Drugs [35].

\section{Samples preparation}

STDs, QCs and patient samples were thawed at room temperature, and $500 \mu \mathrm{L}$ of plasma were pipetted into a $2 \mathrm{~mL}$ polytetrafluoroethylene tube; $25 \mu \mathrm{L}$ of IS working solution were added to each tube. Samples were extracted by protein precipitation using $750 \mu \mathrm{L}$ of acetonitrile. Each sample was vortexed for $30 \mathrm{~s}$ and then centrifuged at $8,000 \mathrm{~g}$ for $10 \mathrm{~min}$. Supernatant was resuspended in $250 \mu \mathrm{L}$ of mobile phase after evaporation to dryness and then transferred to vials for injection in column $(50 \mu \mathrm{L})$. All procedure was carried out at room temperature.

\section{Chromatographic system and conditions}

HPLC was performed with a LaChrom Elite system (VWR International, Milan, Italy) equipped with autosampler, spectrophotometer, and heated column compartment. System management and data acquisition were performed with the EzChrom Elite software. Separation was achieved with a C18 Reverse Phase column (LiChroCART ${ }^{\circ}$ 250-4 LiChrospher 100 RP 18, 5 , VWR International, Milan, Italy) preceded by a Security precolumn (LiChroCART ${ }^{\circ} 4-4$ LiChrospher 100 RP 18, $5 \mu$, VWR International, Milan, Italy). Mobile phase consisted of $35 \%$ water, $15 \%$ methanol, $50 \%$ acetonitrile. Analysis was carried out at the constant flow rate of $1 \mathrm{ml} / \mathrm{min}$ at $35^{\circ} \mathrm{C}$ and eluate was monitored at $250 \mathrm{~nm}$. Each run time was $10 \mathrm{~min}$.

\section{Method validation}

Method was validated following recommended FDA procedures over 3 days [36]. Every day, 2 calibration curves and 8 QCs (specifically, 2 samples for each QC concentration) were extracted using the protocol described above and then analyzed to assess linearity, variability, and accuracy.

Linearity: Range within method linearity was tested was from 0.125 to $8 \mu \mathrm{g} / \mathrm{mL}$, according to data available in literature [6,8,11]. Calibration curves, over the concentrations range chosen, were built with the spike height ratios of each STD and IS, and fitted using linear regression. Totally, 6 calibration curves were analyzed, 2 curves for each validation day.

Variability: Variability was assessed as intra and inter day parameter. Intra-day was defined as relative standard deviation (RSD) calculated from the values measured for 8 QCs performed each day at concentration of $5,1,0.25$ and $0.1 \mu \mathrm{g} / \mathrm{mL}$ for VRC and 5, 1, 0.2 and 0.03 $\mu \mathrm{g} / \mathrm{mL}$ for PSC.

Inter-day variability was defined as RSD calculated using the values measured from 24 samples (8 samples/day) at concentration of 5, 1, 0.25 and $0.1 \mu \mathrm{g} / \mathrm{mL}$ for VRC and 5, 1, 0.2 and $0.03 \mu \mathrm{g} / \mathrm{mL}$ for PSC.

The variability was considered acceptable for each QC if it did not exceed $15 \%$, except for the LLOQ for which was accepted $20 \%$ of variation.

Accuracy: Accuracy was assessed as intra- and inter-day parameter. Intra-day was defined as the medium percent deviation from the nominal concentration for 8 QCs performed each day at concentration of 5, 1, 0.25 and $0.1 \mu \mathrm{g} / \mathrm{mL}$ for VRC and 5, 1, 0.2 and $0.03 \mu \mathrm{g} / \mathrm{mL}$ for PSC.

Inter-day was defined as the medium percent deviation from the nominal concentration for 24 samples ( 8 samples/day) at concentration of $5,1,0.25$ and $0.1 \mu \mathrm{g} / \mathrm{mL}$ for VRC and $5,1,0.2$ and $0.03 \mu \mathrm{g} / \mathrm{mL}$ for PSC.

The accuracy was considered acceptable for each QC if it did not exceed $15 \%$, except for the LLOQ for which was accepted $20 \%$ of variation.

Recovery, limit of detection (LOD) and LLOQ: Percent recovery was obtained from the spike height ratio between extracted sample and drug in methanol at equal concentration $(0.25 \mu \mathrm{g} / \mathrm{mL}$ for VRC and PSC, $0.05 \mu \mathrm{g} / \mathrm{ml}$ for IS). Final value was obtained as mean from 15 ratios.

As requested by international guidelines [36], LOD in plasma was defined as the concentration that yields signal to noise ratio of $3 / 1$, while LLOQ, assessed for intra- and inter-day variability and accuracy, was considered the lowest concentration level that could be determined with a RSD $<20 \%$, gaving a signal to noise ratio $5 / 1$.

Selectivity, stability and reproducibility: Interference from endogenous compounds was investigated by analysis of different blank plasma samples.

Stability of VRC and PSC stock solutions, STDs and QCs were investigated prior to start validation of the assay within 3 months of storage at $-20^{\circ} \mathrm{C}$, assessed by variation of heights. If the measured concentration remained within $20 \%$ of nominal concentration, analytes were considered stable.

As requested by international guidelines [36], reproducibility was defined as precision of the method under the same operating conditions over a short period of time. It has been calculated as RSD of values measured for 10 repetitions of the same sample extracted at concentration of $1 \mu \mathrm{g} / \mathrm{mL}$ for VRC and PSC.

\section{Results}

Different percentages of water, methanol and acetonitrile for constitution of mobile phase were tested (10\% water, $10 \%$ methanol, $80 \%$ acetonitrile; $20 \%$ water, $20 \%$ methanol, $60 \%$ acetonitrile). Different flow rates $(0.8 ; 1.2 \mathrm{ml} / \mathrm{min})$, oven temperatures $\left(32 ; 37^{\circ} \mathrm{C}\right)$ and UV wavelength $(230 ; 250 \mathrm{~nm})$ were also tested.

Time of analytical run was chosen at $10 \mathrm{~min}$, according to the retention times of substances and their good separation. VRC and PSC retention times were $3.9 \pm 0.1$ and $7.9 \pm 0.1$, respectively, while it was $7.1 \pm 0.1$ for IS. Representative chromatogram of a blank plasma (plus IS) and VRC and PSC STD2 and STD6 overlying is shown in figure 3.

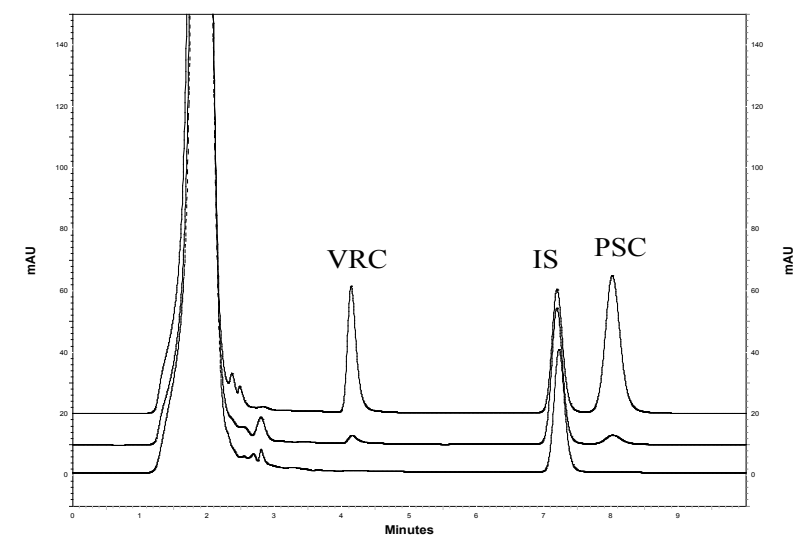

Figure: 3 Representative overlapped chromatograms of extracted plasma samples: blank plus Internal Standard (IS) (line A), blank plus IS and Voriconazole (VRC)/Posaconazole (PSC) STD ${ }_{2}$ (line B) and blank plus IS and VRC/PSC STD 6 (line C) 


\section{Method validation}

Linearity: Calibration curves were linear over the concentrations range selected for validation $(0.125-8 \mu \mathrm{g} / \mathrm{mL})$, with a mean regression coefficient $\left(\mathrm{r}^{2}\right)$ of 0.99 for both analytes.

\section{Variability, accuracy, recovery, LOD and LLOQ.}

Variability and accuracy, assessed as intra- and inter-day parameters, are listed in table 2 . All observed data were below $15.0 \%$, with the only exception for QC medium value of PSC that was $15.78 \%$ for intra-day accuracy. Observed recovery was around $100 \%$ for both analytes. LLOQ was set at $0.1 \mu \mathrm{g} / \mathrm{mL}$ for VRC and $0.03 \mu \mathrm{g} / \mathrm{mL}$ for PSC, prior to start validation of the assay, while LOD was set at $0.05 \mu \mathrm{g} / \mathrm{mL}$ for VRC and $0.02 \mu \mathrm{g} / \mathrm{mL}$ for PSC.

Selectivity, stability and reproducibility: No signal increase due to endogenous plasma substances was observed at the retention time of analytes of interest. VRC and PSC stock solutions, plasma STDs and QCs were stable within 3 months of storage at $-20^{\circ} \mathrm{C}$; measured concentration remained within $20 \%$ of nominal concentration. RSD observed of method reproducibility was $0.29 \%$ for VRC and $0.88 \%$ for PSC.

Patients: Validated assay has been applied to azoles quantification of 65 plasma samples of 23 AML patients treated with VRC and 40 plasma samples of 14 AML patients treated with PSC.

Patients data are reported in table 3 , divided by sex. VRC C trough ranged from 0 to $7 \mu \mathrm{g} / \mathrm{mL}$, while PSC C trough ranged from 0.08 to 2.06 $\mu \mathrm{g} / \mathrm{mL}$, according to data present in literature $[6,8,11]$.

Positive results obtained from proficiency testing program ${ }^{35}$ showed that the method allows correct quantification of analytes in plasma samples, becoming useful for clinical routine of antifungal therapy TDM.

\section{Discussion}

Antifungal TDM is an important tool in clinical practice, especially for patients with haematological disorders, in order to avoid drug dose related toxicity and improve clinical outcome. Due to specific metabolic pathways of triazoles, drug interactions in selected patients, such as AML patients, may often cause sub-therapeutic concentrations. In particular, VRC is a substrate and inhibitor of CYP2C19, CYP2C8/9 and CYP3A4 [1,2] and PSC is an inhibitor of CYP3A4, metabolized by glucuronidation ${ }^{4}$. Due to the metabolic bind especially at CYP3A4 site between azoles and current therapy for AML treatment, and to therapeutic window $(1-5,5 \mu \mathrm{g} / \mathrm{mL})$ reported for VRC [8], and thresholds of efficacy reported for PSC $(0.7 \mu \mathrm{g} / \mathrm{mL}$ for prophylaxis and $1.25 \mathrm{mg} / \mathrm{mL}$ for treatment $)^{11,12}$, antifungal TDM is gaining increasingly importance for selected populations such as AML patients. Considering this interest, we have developed and fully validated a new HPLC-UV methodology to measure VRC and PSC in human plasma. During development and optimization of our methodology, best results were achieved at $35 \%$ water, $15 \%$ methanol, $50 \%$ acetonitrile of mobile phase, constant flow rate of $1 \mathrm{ml} / \mathrm{min}, 35^{\circ} \mathrm{C}$ and $250 \mathrm{~nm}$. In our opinion, more complete assay reported in literature using HPLC-UV is that from Gordien et al. [37]. With description of methodology able to simultaneously quantify fluconazole, PSC, VRC, ketoconazole, itraconazole and its metabolite. Although this method allows quantification of the five azoles plus metabolite in a single assay, plasma samples were purified by solid-phase extraction procedure, which is more expensive than our developed procedure for extraction. They also used linezolid as IS, an antibiotic which may be co-administered in clinical practice, while the use of flavone, as we set in our methodology, makes our method more applicable to the analysis of immunocompromized patients. More recently LC-MS/MS methods have been developed to the purpose of antifungal TDM [25-32], but MS facilities are not always available in standard hospital laboratories. Our developed method, based on HPLC-UV system, reveals a good performance to this aim. Even if VRC and PSC are not co-administered, our chromatographic method allows the quantification of both analytes using a single calibration curve, extraction procedure, and HPLC system. Therefore, plasma samples of patients taking VRC or PSC could be analyzed simultaneously,

\begin{tabular}{|c|c|c|c|c|c|c|c|c|c|c|c|c|c|c|c|}
\hline \multicolumn{16}{|c|}{ VORICONAZOLE } \\
\hline \multicolumn{4}{|c|}{$\mathrm{QC}_{1}(0.25 \mu \mathrm{g} / \mathrm{mL})$} & \multicolumn{4}{|c|}{$\mathrm{QC}_{\mathrm{m}}(1 \mu \mathrm{g} / \mathrm{mL})$} & \multicolumn{4}{|c|}{$Q C_{h}(5 \mu \mathrm{g} / \mathrm{mL})$} & \multicolumn{4}{|c|}{ LLOQ $(0.1 \mu \mathrm{g} / \mathrm{mL})$} \\
\hline \multicolumn{2}{|c|}{ Accuracy } & \multicolumn{2}{|c|}{ Variability } & \multicolumn{2}{|c|}{ Accuracy } & \multicolumn{2}{|c|}{ Variability } & \multicolumn{2}{|c|}{ Accuracy } & \multicolumn{2}{|c|}{ Variability } & \multicolumn{2}{|c|}{ Accuracy } & \multicolumn{2}{|c|}{ Variability } \\
\hline $\begin{array}{l}\text { intra- } \\
\text { day }\end{array}$ & $\begin{array}{l}\text { inter- } \\
\text { day }\end{array}$ & $\begin{array}{l}\text { intra- } \\
\text { day }\end{array}$ & $\begin{array}{l}\text { inter- } \\
\text { day }\end{array}$ & $\begin{array}{l}\text { intra- } \\
\text { day }\end{array}$ & $\begin{array}{l}\text { inter- } \\
\text { day }\end{array}$ & $\begin{array}{l}\text { intra- } \\
\text { day }\end{array}$ & $\begin{array}{l}\text { inter- } \\
\text { day }\end{array}$ & $\begin{array}{l}\text { intra- } \\
\text { day }\end{array}$ & $\begin{array}{l}\text { inter- } \\
\text { day }\end{array}$ & $\begin{array}{c}\text { intra- } \\
\text { day }\end{array}$ & inter-day & $\begin{array}{l}\text { intra- } \\
\text { day }\end{array}$ & $\begin{array}{l}\text { inter- } \\
\text { day }\end{array}$ & $\begin{array}{l}\text { intra- } \\
\text { day }\end{array}$ & inter-day \\
\hline 10.28 & 10.26 & 3.50 & 5.71 & 7.07 & 7.40 & 3.85 & 7.28 & 3.64 & 3.41 & 3.30 & 3.26 & 13.39 & 13.02 & 8.42 & 8.97 \\
\hline \multicolumn{16}{|c|}{ POSACONAZOLE } \\
\hline \multicolumn{4}{|c|}{$\mathrm{QC}_{1}(0.2 \mu \mathrm{g} / \mathrm{mL})$} & \multicolumn{4}{|c|}{$Q C_{m}(1 \mu \mathrm{g} / \mathrm{mL})$} & \multicolumn{4}{|c|}{$Q C_{h}(5 \mu g / m L)$} & \multicolumn{4}{|c|}{ LLOQ $(0.03 \mu \mathrm{g} / \mathrm{mL})$} \\
\hline \multicolumn{2}{|c|}{ Accuracy } & \multicolumn{2}{|c|}{ Variability } & \multicolumn{2}{|c|}{ Accuracy } & \multicolumn{2}{|c|}{ Variability } & \multicolumn{2}{|c|}{ Accuracy } & \multicolumn{2}{|c|}{ Variability } & \multicolumn{2}{|c|}{ Accuracy } & \multicolumn{2}{|c|}{ Variability } \\
\hline $\begin{array}{l}\text { intra- } \\
\text { day }\end{array}$ & $\begin{array}{l}\text { inter- } \\
\text { day }\end{array}$ & $\begin{array}{l}\text { intra- } \\
\text { day }\end{array}$ & $\begin{array}{c}\text { inter- } \\
\text { day }\end{array}$ & $\begin{array}{l}\text { intra- } \\
\text { day }\end{array}$ & $\begin{array}{l}\text { inter- } \\
\text { day }\end{array}$ & $\begin{array}{l}\text { intra- } \\
\text { day }\end{array}$ & $\begin{array}{l}\text { inter- } \\
\text { day }\end{array}$ & $\begin{array}{l}\text { intra- } \\
\text { day }\end{array}$ & $\begin{array}{c}\text { inter- } \\
\text { day }\end{array}$ & $\begin{array}{l}\text { intra- } \\
\text { day }\end{array}$ & inter-day & $\begin{array}{l}\text { intra- } \\
\text { day }\end{array}$ & $\begin{array}{l}\text { inter- } \\
\text { day }\end{array}$ & $\begin{array}{l}\text { intra- } \\
\text { day }\end{array}$ & inter-day \\
\hline 10.43 & 10.87 & 7.70 & 10.78 & 15.78 & 14.71 & 4.28 & 4.76 & 5.38 & 5.16 & 3.18 & 3.25 & 13.78 & 13.18 & 7.88 & 7.88 \\
\hline
\end{tabular}

Table 2:Validation data for Quality Controls (low, medium, high) and Lower Limit of Quantification (LLOQ) concentrations for voriconazole and posaconazole.Values are expressed as percent Relative Standard Deviation.

\begin{tabular}{|c|c|c|c|}
\hline \multicolumn{4}{|l|}{ VORICONAZOLE } \\
\hline SEX & MEAN C ${ }_{\text {TROUGH }}$ & UPPER C $\mathrm{CROUGH}$ & LOWER $C_{\text {TROUGH }}$ \\
\hline MALE $\left(N^{*}=13\right)$ & $1.46 \pm 1.40$ & 6.81 & 0 \\
\hline FEMALE $\left(N^{*}=10\right)$ & $1.29 \pm 1.55$ & 7.00 & 0 \\
\hline \multicolumn{4}{|l|}{ POSACONAZOLE } \\
\hline SEX & MEAN C & UPPER C TROUGH & LOWER $\mathrm{C}_{\mathrm{TROUGH}}$ \\
\hline $\operatorname{MALE}\left(\mathrm{N}^{*}=11\right)$ & $0.49 \pm 0.42$ & 2.06 & 0.08 \\
\hline FEMALE $\left(\mathrm{N}^{*}=3\right)$ & $0.57 \pm 0.46$ & 1.19 & 0.08 \\
\hline
\end{tabular}

*: number of patients.

Table 3:Pharmacokinetic data of patients treated with voriconazole and posaconazole. Concentrations are expressed as $\mu \mathrm{g} / \mathrm{mL}$. Mean C standard deviation. 
reducing costs and time required for analysis. Furthermore our calibration curves, cover all drug concentrations achieved in patients followed at our institution and reported in published pharmacokinetics studies[21,38-41], making our method useful for routine analysis, especially for TDM application, where receiving a report quickly may help clinicians to eventually modify antifungal drug dose during therapy. Mean regression coefficient of calibration curves obtained during validation indicates an excellent linearity of the methodology developed; accuracy, intra- and inter-day variability data, listed in Table 2, are all acceptable but one. High extraction efficiency shows a good final recovery and absence of interference peaks at the analytes retention times, lets an accurate measurement of azoles plasma levels. The LLOQ $(0.1$ and $0.03 \mu \mathrm{g} / \mathrm{mL}$ for VRC and PSC, respectively) of the developed assay makes methodology suitable to perform azoles therapeutic monitoring in AML patients treated with these drugs for fungal infections. Moreover, the total run time is shorter than those proposed using UV detection in literature (10 $\mathrm{min}$ vs 19 and $15 \mathrm{~min}$ ) [29,37].

The developed method is currently used in our laboratory service to monitor VRC and PSC concentrations in plasma of patients for antifungal therapy. To the purpose of this paper, the methodology developed was applied to 65 plasma samples obtained from 23 AML patients receiving VRC and 40 plasma samples of 14 AML patients receiving PSC. There were no samples with concentrations above the upper limit of quantification $(8 \mu \mathrm{g} / \mathrm{mL}$ for both analytes). Although the concentrations of patients samples varied widely, they were well encompassed by the concentrations range of our standard curves. Of 105 samples analyzed, a high number of sub-therapeutic plasma concentrations were observed. Especially for PSC, where only 12 of 40 samples (30\%) were above the expected threshold of efficacy. For VRC, among the 65 samples analyzed, 29 (44.6\%) were in the expected range $(1-5.5 \mu \mathrm{g} / \mathrm{mL}), 34(52.3 \%)$ were $<1 \mu \mathrm{g} / \mathrm{mL}$, while $2(3 \%)$ were $5.5 \mu \mathrm{g} / \mathrm{mL}$. Data observed indicate need to increase antifungal dose in patients treated for AML, but, on the other hand, lead to pay attention to that AML treatment can be affected by azoles therapy via interaction at CYP3A4 site.

Finally no statistically significant difference was observed between azoles concentrations gender related, even if male patients achieved a major mean concentration of VRC levels than females (1.46 \pm 1.40 vs $1.29 \pm 1.55)$, while for PSC trend observed was reverse $(0.49 \pm 0.42$ vs $0.57 \pm 0.46)$.

\section{Conclusion}

A simple, robust and reliable HPLC-UV method for the determination of VRC and PSC in human plasma has been developed, validated and described.

\section{References}

1. Worth LJ, Blyth CC, Booth DL, Kong DC, Marriott D, et al. (2008) Optimizing antifungal drug dosing and monitoring to avoid toxicity and improve outcomes in patients with haematological disorders. Intern Med J. 38: 521-537.

2. Mathew BP, Nath M (2009) Recent approaches to antifungal therapy for invasive mycoses. ChemMedChem 4: 310-323.

3. Ghosal A, Hapangama N, Yuan Y AchanfuoYJ, lannucci R, et al. (2004) Identification of human UDP-glucuronosyltransferase enzyme(s) responsible for the glucuronidation of posaconazole (Noxafil). Drug Metab Dispos 32: 267-271.

4. Strzinger D, Swoboda S, Lichtenstern C, Mller C, Weigand MA, et al. (2008) Development and validation of a high-performance liquid chromatography assay for posaconazole utilizing solid-phase extraction. Clin Chem Lab Med 46: $1747-1751$

5. Lewis RE (2006) Managing drug interactions in the patient with aspergillosis.
Med Mycol 44: 349-356.

6. Hope WW, Billaud EM, Lestner J, Denning DW (2008) Therapeutic drug monitoring for triazoles. Curr Opin Infect Dis 21: 580-586.

7. Brggemann RJ, Alffenaar JW, Blijlevens NM, Billaud EM, Kosterink JG, et al. (2009) Clinical relevance of the pharmacokinetic interactions of azole antifungal drugs with other coadministered agents. Clin Infect Dis 48: 1441-1458.

8. Pascual A, Calandra T, Bolay S, Buclin T, Bille J, et al. (2008) Voriconazole therapeutic drug monitoring in patients with invasive mycoses improves efficacy and safety outcomes. Clin Infect Dis 46: 201-211.

9. Shimizu T, Ochiai H, Asell F, Shimizu H, Saitoh R, et al. (2003) Bioinformatics research on inter-racial difference in drug metabolism I. Analysis on frequencies of mutant alleles and poor metabolizers on CYP2D6 and CYP2C19. Drug Metab Pharmacokinet18: 48-70.

10. Trifilio S, Pennick G, Pi J, Zook J, Golf M, et al. (2007) Monitoring plasma voriconazole levels may be necessary to avoid subtherapeutic levels in hematopoietic stem cell transplant recipients. Cancer.109:1532-1535.

11. Jang SH, Colangelo PM, Gobburu JV (2010) Exposure-response of posaconazole used for prophylaxis against invasive fungal infections: evaluating the need to adjust doses based on drug concentrations in plasma. Clin Pharmacol Ther 88:115-119.

12. Walsh TJ, Raad I, Patterson TF, Chandrasekar P, Donowitz GR, et al. (2007) Treatment of invasive aspergillosis with posaconazole in patients who are refractory to or intolerant of conventional therapy: an externally controlled trial. Clin Infect Dis44: 2-12.

13. Chhun S, Rey E, Tran A, Lortholary O, Pons G, et al. (2007) Simultaneous quantification of voriconazole and posaconazole in human plasma by highperformance liquid chromatography with ultra-violet detection. J Chromatogr B Anal Technol Biomed Life Sci 852: 223-228.

14. Gage R, Stopher DA (1998) A rapid HPLC assay for voriconazole in human plasma. J Pharm Biomed Anal 17: 1449-1453.

15. Nakagawa S, Suzuki R, Yamazaki R, Kusuhara Y, Mitsumoto S, et al. (2008) Determination of the antifungal agent voriconazole in human plasma using a simple column-switching high-performance liquid chromatography and its application to a pharmacokinetic study. Chem Pharm Bull (Tokyo) 56: 328-331.

16. Pascual A, Nieth V, Calandra T, Bille J, Bolay S, et al. (2007) Variability of voriconazole plasma levels measured by new high-performance liquid chromatography and bioassay methods. Antimicrob Agents Chemother 51: 137-143.

17. Phourcq F, Jarry C, Bannwarth B (2004) Direct injection HPLC micro method for the determination of voriconazole in plasma using an internal surface reversed-phase column. Biomed Chromatogr 18: 719-722.

18. Simmel F, Soukup J, Zoerner A, Radke J, Kloft C (2008) Development and validation of an efficient HPLC method for quantification of voriconazole in plasma and microdialysate reflecting an important target site. Anal Bioanal Chem 392: 479-488.

19. Stopher D A, Gage R. (1997) Determination of a new antifungal agent voriconazole, by multidimensional high-performance liquid chromatography with direct plasma injection onto a size-exclusion column. J Chromatogr B Biomed Sci. Appl. 691: 441-448.

20. Gordien JB, Pigneux A, Vigouroux S, Tabrizi R, Accoceberry I, et al. (2009) Simultaneous determination of five systemic azoles in plasma by highperformance liquid chromatography with ultraviolet detection. J Pharm Biomed Anal 50: 932-938.

21. Zhang M, Moore GA, Barclay ML, Begg EJ (2013) A simple high-performance liquid chromatography method for simultaneous determination of three triazole antifungals in human plasma. Antimicrob Agents Chemother 57: 484-489.

22. Pennick GJ, Clark M, Sutton DA, Rinaldi MG (2003) Development and validation of a high-performance liquid chromatography assay for voriconazole. Antimicrob Agents Chemother 47: 2348-2350.

23. Wenk M, Droll A, Krhenbhl S (2006) Fast and reliable determination of the antifungal drug voriconazole in plasma using monolithic silica rod liquid chromatography. $J$ Chromatogr B Analyt Technol Biomed Life Sci 832: 313-316.

24. Khoschsorur G, Fruehwirth F, Zelzer S (2005) Isocratic high-performance liquid chromatographic method with ultraviolet detection for simultaneous determination of levels of voriconazole and itraconazole and its hydroxy metabolite in human serum. Antimicrob Agents Chemother 49: 3569-3571. 
Citation: Francia SD, Cardalana MLT, Pirro EP, Piccione FM, Abbadessa G, et al. (2015) A New HPLC Validated Method for Therapeutic Monitoring Of Triazoles in Human Plasma: First Results in Leukaemic Patients Clin Exp Pharmacol 5: 189. doi:10.4172/2161-1459.1000189

25. Baietto L, D'Avolio A, Ventimiglia G, De Rosa FG, Siccardi M, et al. (2010) Development, validation, and routine application of a high-performance liquid chromatography method coupled with a single mass detector for quantification of itraconazole, voriconazole, and posaconazole in human plasma. Antimicrob Agents Chemother.54: 3408-3413.

26. Alffenaar JW, Wessels AM, van Hateren K, Greijdanus B, Kosterink JG, et al. (2010) Method for therapeutic drug monitoring of azole antifungal drugs in human serum using LC/MS/MS. J Chromatogr B Analyt Technol Biomed Life Sci 878: 39-44

27. Beste KY, Burkhardt O, Kaever V (2012) Rapid HPLC-MS/MS method for simultaneous quantitation of four routinely administered triazole antifungals in human plasma. Clin Chim Acta 413: 240-245.

28. Decosterd LA, Rochat B, Pesse B, Mercier T, Tissot F, et al. (2010) Multiplex ultraperformance liquid chromatography-tandem mass spectrometry method for simultaneous quantification in human plasma of fluconazole, itraconazole, hydroxylitraconazole, posaconazole, voriconazole, voriconazole-Noxide, anidulafungin, and caspofungin. Antimicrob Agents Chemother 54: 5303-5315.

29. Verdier MC, Bentu-Ferrer D, Tribut O, Bellissant E (2010) Liquid chromatography-tandem mass spectrometry method for simultaneous quantification of four triazole antifungal agents in human plasma. Clin Chem Lab Med 48: 1515-1522.

30. Keevil BG, Newman S, Lockhart S, Howard SJ, Moore CB, et al. (2004) Validation of an assay for voriconazole in serum samples using liquid chromatography-tandem mass spectrometry. Ther Drug Monit 26: 650-657.

31. Vogeser M, Schiel X, Sphrer U (2005) Quantification of voriconazole in plasma by liquid chromatography-tandem mass spectrometry. Clin Chem Lab Med 43: $730-734$.

32. Egle H, Trittler R, Knig A, Kmmerer K (2005) Fast, fully automated analysis of voriconazole from serum by LC-LC-ESI-MS-MS with parallel column-switching technique. J Chromatogr B Analyt Technol Biomed Life Sci 814: 361-367.
33. Michael C, Teichert J, Preiss R (2008) Determination of voriconazole in human plasma and saliva using high-performance liquid chromatography with fluorescence detection. J Chromatogr B Analyt Technol Biomed Life Sci 865:74-80

34. Shen JX, Krishna G, Hayes RN (2007) A sensitive liquid chromatography and mass spectrometry method for the determination of posaconazole in human plasma. J Pharm Biomed Anal 43: 228-236.

35. Lempers VJ, Alffenaar JW, Touw DJ, Burger DM, Uges DR, et al. (2014) Five year results of an international proficiency testing programme for measurement of antifungal drug concentrations. J Antimicrob Chemother 69: 2988-2994.

36. Center for Drug Evaluation and Research of the U.S. Department of Health and Human Services Food and Drug Administration, 2001.

37. Gordien JB, Pigneux A, Vigouroux S, Tabrizi R, Accoceberry I, et al. (2009) Simultaneous determination of five systemic azoles in plasma by highperformance liquid chromatography with ultraviolet detection. J Pharm Biomed Anal 50: 932-938.

38. Barone JA, Koh JG, Bierman RH, Colaizzi JL, Swanson KA, et al. (1993) Food interaction and steady-state pharmacokinetics of itraconazole capsules in healthy male volunteers. Antimicrob Agents Chemother 37: 778-784.

39. Hardin TC, Graybill JR, Fetchick R, Woestenborghs R, Rinaldi MG, et al. (1988) Pharmacokinetics of itraconazole following oral administration to normal volunteers. Antimicrob Agents Chemother 32: 1310-1313.

40. Lazarus HM, Blumer JL, Yanovich S, Schlamm H, Romero A (2002) Safety and pharmacokinetics of oral voriconazole in patients at risk of fungal infection: a dose escalation study. J Clin Pharmacol 42: 395-402.

41. Ullmann AJ, Cornely OA, Burchardt A, Hachem R, Kontoyiannis DP, et al (2006) Pharmacokinetics, safety, and efficacy of posaconazole in patients with persistent febrile neutropenia or refractory invasive fungal infection. Antimicrob Agents Chemother 50: 658-666. 